\title{
A Gestão de
}

\section{Competências Gerencials}

\section{e A Contribuição dA}

\section{Aprendizagem}

\section{Organizacional -}

\section{A EXPERIÊNCIA de TrÊs}

\section{Empresas Australianas}

CLAUDIA BITENCOURT

ProfessoraAdjunta emAdministração de RecursosHumanosna

Universidadedo Vale do Rio dosSinos

Doutora emAdministração - Reaursos Humanos

E-mail:daudia.ez@terra.com.br 


\section{RESUM O}

Tendo em vista o cenário competitivo e a necessidade de desenvolvimento gerencial para acompanhar e gerar as mudanças desejadas no ambiente organizacional, muitas empresas começam a repensar a gestão das competências. Nesse contexto, as tradicionais práticas de treinamento e desenvolvimento parecem não responder àsnovas demandasorganizacionais. Este paper apresenta a A prendizagem Organizacional como uma estratégia que busca viabilizar o desenvolvimento de competências gerenciais baseado nosprincípios da interação, da articulação e da ênfase ao coletivo, característico dessa abordagem. A pesquisa de campo apresentada ilustra práticas organizacionais de três empresas australianas, enfatiza as questões da consciência coletiva representada através da iniciativa governamental e da formalidade e informalidade na gestão dascompetênciasgerenciais.

\section{P A L A VRA S-CHAVE}

Gestão de competências, Aprendizagem organizacional, Empresas australianas.

\section{A B STR A CT}

Having in mind the competitive scenario and the need for managerial development to accompany and to generate the wished changes in the organizational environment, many companiesstart to rethink their competencies management. In thisnew context, the traditional practices of training seem to be inappropriate to the new organizational necessity. This paper presents the Organizational Learning as a strategy that intends to develop managerial competencies based on some principlesas: interaction, articulation and collective practices. The research presents some practices that were observed in three Australian companies. These practices emphasize the collective conscience witch is represented by governmental initiatives and the formal and informal practices.

KEYWORDS

Competence management, Organizational learning, Australian companies.

\section{INTRODUÇÃ O}

As "novas fontes de vantagem competitiva" (Hamel e Prahalad, 1995) e as 
"novas correntes de negócios" (Kanter, 1997) têm exigido mudançascada vez mais rápidas, profundase abrangentes nas organizações. Sendo assim, observa-se a crescente necessidade de envolver e desenvolver as pessoas para que as mudanças requeridas sejam efetivas. Neste contexto, porém, as tradicionais práticas de treinamento e desenvolvimento não conseguem responder a essas novasdemandas.

A argumentação focalizada neste trabalho refere-se à contradição entre a formação tradicional e as novas competências esperadas do gestor. Nesse sentido, acredita-se que a A prendizagem Organizacional possa contribuir para o desenvolvimento de competências gerenciais, oferecendo uma visão dinâmica e interativa na construção de estratégias voltadasà formação de gesto res em contraste às práticas tradicionais de formação gerencial baseadas exclusivamente em treinamento.

Para este trabalho serão desenvolvidasas seguintes seções: primeiramente apresentam-se os conceitos e principais correntesteóricas referentesà competência gerencial; na seção dois discute-se a multiplicidade de abordagem referente à aprendizagem organizacional; em seguida, a aprendizagem organizacional é tratada como um elemento que contribui para a formação gerencial e o desenvolvimento de competências; na seção quatro apresenta-se o Programa Australiano de Desenvolvimento de Competências, ilustrando a parceria entre governo e empresas; na seção cinco são desenvolvidostrês estudos de caso de empresas australianas ilustrando as práticas voltadas ao desenvolvimento de competências gerenciais e a contribuição da aprendizagem organizacio nal neste processo; por fim, apresenta-se a conclusão desta análise.

\section{O DESENVOLVIMENTO DE COMPETÊNCIA GERENCIAL}

Os modelos de competências gerenciais são propostas que apresentam um amplo escopo de reflexões acerca dasnecessidades de planejamento, desenvolvimento e acompanhamento do perfil e formação gerencial a partir da realidade individual e estratégia competitiva de cada empresa, fato esse que caracteriza uma visão processual (desenvolvimento de competência), diferenciando-se de construtos que priorizam a listagem de atributos que por si só não agregam valor à organização ou às pessoas.

Conforme Le Boterf (1997:22), 
- A GESTÃO DE COM PETÊNNCIAS GERENCIAISEA CONTRIBUIÇÃO DA APRENDIZAGEM ORGANIZACIONAL・•

Nesse contexto, apresenta-se a A prendizagem Organizacional como uma estratégia que busca aproximar e integrar a competência essencial (core competence) e gerencial. Conforme Ruas (1999:8),

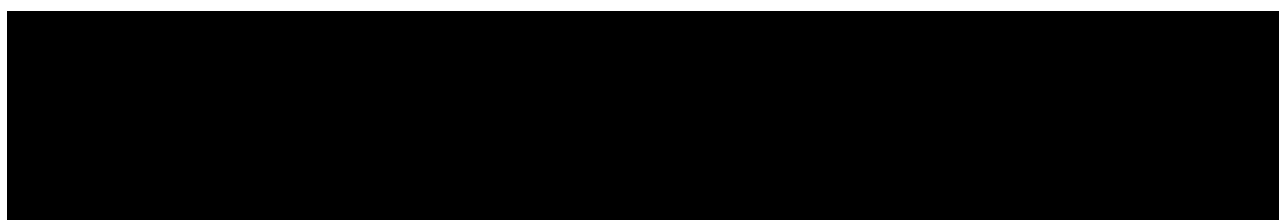

Ou seja, a aprendizagem está orientada para o desenvolvimento de competências(humanas e organizacionais).

A partir da análise das várias correntes de estudos (francesa, americana, latino-americana, brasileira) acerca da questão das competências, destaca-se que o conceito de competência está relacionado aos seguintes aspectos:

1. Desenvolvimento de conceitos, habilidadese atitudes (formação) (Zarifian, 1996; Ropé e Tanguy, 1997; Durand, 1999; Dutra e Silva, 1998).

2. Práticas de trabalho, capacidade de mobilizar recursos, fato esse que a difere do conceito de potencial (ação) (M oscovici, 1994; Gallart e Jacinto, 1995; Magalhãese Rocha, 1997; Kubr e Abell, 1998, Le Boterf, 1997).

3. O objetivo do desenvolvimento da competência está relacionado à busca de melhores desempenhos (resultados) (Dutra e Silva 1998; Sparrow e Bognanno apud Ribeiro e Guimarães, 1999; Fleury, 1999).

4. A definição de competências deve ser constantemente questionada (perspectiva dinâmica) (Spencer Jr., 1993; Ruas, 1999; Eboli, 1999).

5. A responsabilidade maior desse processo deve ser atribuída ao próprio indivíduo (auto-desenvolvimento) (Spencer, L. e Spencer, S., 1993; Vergaro, 1995).

6. O desenvolvimento de competência ocorre a partir do relacionamento com outras pessoas (interação) (Sandberg, 2000).

Questões relacionadas à formação, ação, resultados, perspectiva dinâmica, auto-desenvolvimento e interação também são fundamentais ao se tratar da aprendizagem (seja individual ou organizacional). Portanto, as duas abordagenspossuem uma interessante relação de complementaridade, na qual cria-se um ciclo virtuoso no qual a aprend izagem contribui para o desenvolvimento de competênciase, ao mesmo tempo, para que esta aprendizagem seja factível é preciso investir em desenvolvimento de competências.

\section{A APRENDIZAGEM ORGANIZACIONAL E A MULTIPLICIDADE DE ENFOQUES}

A pesar de ser vasta e crescente a literatura referente ao tema aprendiza- 
gem organizacional, existe muita discordância em relação ao que é e como ocorre a aprendizagem. Conforme Dodgson (1993:376-377),

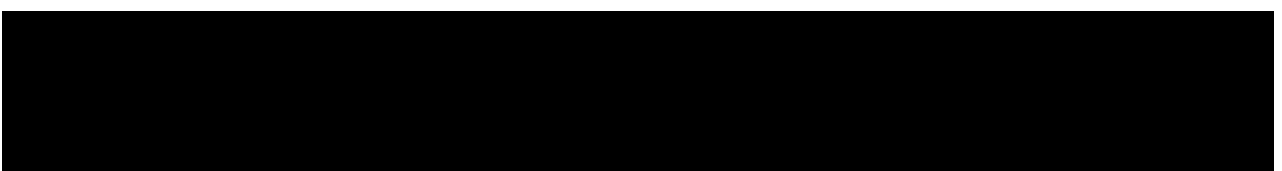

A ênfase, para este grupo, recai sobre a quantificação de resultados. Para osadministradores, contudo, a aprendizagem é vista como uma "vantagem competitiva sustentável", e a literatura aborda o tema como uma estratégia inovadora eficiente. Ospsicólogos, por sua vez, encaram a aprendizagem examinando o processo, ou seja, a maneira como as organizações constroem e organizam seus conhecimentos e suas rotinas observando suas atividades e cultura organizacional e adaptando e desenvolvendo a eficiência organizacional através da melhoria de habilidades em relação à força de trabalho. Para os pedagogos, enfim, a ênfase refere-se ao indivíduo e como este constrói a sua aprendizagem a partir de sua própria realidade e necessidade (ênfase na aprendizagem individual).

O referencial conceitual desenvolvido por pesquisadores na área traz à tona a questão da multiplicidade de enfoquesem relação ao tema. Neste sentido, alguns autores focalizam-se na questão do processo de aprendizagem (organizational learning), como Argyris (1992), Kim (1993), Vaill (1996), Nonaka eTakeuchi (1997), Kolb (1997), enquanto outros, no produto da aprendizagem (learning organization), como Senge (1990), M organ (1996), Garvin (1998), M arquardt (1996) e Swieringa e Wierdsma (1992). É importante diferenciar os termos ap rendizagem organizacional e organização de aprendizagem que, muitas vezes, são utilizados indiscriminadamente. Quando a referência é a organização de aprendizagem, o foco refere-se a questionamentos do tipo "o que" e descreve os sistemas, princípio se características da organização que aprende como uma entidade coletiva (perspectiva descritiva). A aprendizagem organizacional, por sua vez, refere-se ao "como" a aprendizagem na organização acontece, isto é, as habilidades e processos de construção e utilização do conhecimento (perspectiva processual). Segundo Marquardt (1996:19), a "aprendizagem organizacional é uma das dimensões ou elemento da organização de aprendizagem".

Destaca-se que para estepaper interessam os conceitosrelacionadosà aprendizagem organizacional ( organizational learning). Assim, a partir de uma revisão teórica e de uma reflexão a respeito dos trabalhos desenvolvidos nesta área, observa-se que existem alguns pontos em comum que se referem ao conceito de aprendizagem organizacional:

- $\quad$ processo (em termos de continuidade);

- transformação (baseado na mudança de atitude);

- grupo (enfatizando o coletivo); 
- A GESTÃO DE COM PETÊNNCIAS GERENCIAISEA CONTRIBUIÇÃO DA APRENDIZAGEM ORGANIZACIONAL・•

- criação e reflexão (sob a óptica da ino vação e conscientização);

- ação (apropriação e disseminação do conhecimento tendo como referência uma visão pragmática).

Tendo em vista o desenvolvimento de competências gerenciais, os autores que mais se dedicam a esta questão são: Kolb (1997), Senge (1990), Argyris (1992), Swieringa e Wierdsma (1992) e Nonaka e Takeuchi (1997), discutidos na seção seguinte.

\section{O DESENVOLVIMENTO DE COMPETÉNCIA GERENCIAL E A APRENDIZAGEM ORGANIZACIONAL}

A pesar da "cumplicidade" existente entre as abordagensapresentadas, existe uma carência no que se refere à explicitação desta relação. Esta seção busca relacionar alguns trabalhos desenvolvidos por pesquisadores da área de aprendizagem organizacional (Kolb, Argyris, Senge, Swieringa \& Wierdsma, Nonaka $\&$ Takeuchi) com a abordagem referente ao desenvolvimento de competência gerencial. As questões apresentadas são construtos da autora não existindo, entretanto, a pretensão, neste momento, de esgotar o assunto mas de apenascontribuir para o aprofundamento de algumas reflexões a seguir apresentadas.

A abordagem desenvolvida por David Kolb (1997) centraliza-se no desenvolvimento do ciclo de aprendizagem vivencial. Este estudo propicia a visão processual no que se refere à aprendizagem e formação de competência destacando a importância da ação e reflexão num processo contínuo que visa equilibrar as ações e abstrações caracterizadas neste ciclo.

Argyris (1992), por sua vez, dedica-se à discussão do gap observado entre a teoria assumida e em uso (discurso e prática). Neste momento, ressalta-se a necessidade de tratar a competência enquanto práticas observadas no ambiente de trabalho, fato esse que a diferencia do desenvolvimento de potencial. Argyris destaca, ainda, a importância de (re)pensar o processo de desenvolvimento de competência a partir do erro e assim oportunizar o desenvolvimento do double loop learning ${ }^{1}$ evitando o desenvolvimento de incompetência hábil?.

Senge (1990), a partir do desenvolvimento de cinco disciplinas, trata a questão da competência indiretamente. Assim, o domínio pessoal pode ser interpretado como uma necessidade de desenvolver as pessoas a partir do au-

1 Double looping learning acontece a partir de desencontros que são questionadose alteram a orientação natural da ação ( governing variable). Acontece quando busca-se a causa que gera os problemase não 0 tratamento de sintomas.

2 A incompetência hábil se estabelece porque sempre que se é habilidoso em algo, age-se de forma automática, sem questionar o que se faz, ou o porquê. Simplesmente, acredita-se que aquilo é o certo, sem prestar atenção às ações. 
toconhecimento, ou seja autodesenvolvimento. Os modelos mentais referemse à reflexão em ação, onde questiona-se as práticas usuais observadas nas rotinas de trabalho procurando agregar valor àsatividades da empresa a partir de uma postura mais crítica e criativa. 0 trabalho com equipes retoma a importância da interação como um processo de desenvolvimento de competências coletivase ind ividuais assim como o desenvolvimento de objetivo comum ou compartilhado. Esse último aponta ainda para a necessidade de construir uma realidade a partir das especificidades de cada organização, fato esse que remete à visão limitada acerca da competência como uma lista de atributos. 0 raciocínio sistêmico, por sua vez, destaca a importância da visão processual, em contraste à visão de evento baseada em treinamentos formais para o desenvolvimento e formação de gestores.

Swieringa e W ierdsma (1992) destacam a importância das regras, insights e princípios para a formação do comportamento organizacional e desenvolvimento de competência. Em síntese, a organização consiste em uma combinação de regras, insightse princípios. As primeiras formulam o que se deve fazer, o que é permitido; os segundos representam o que se sabe e se entende (influência indireta); e os terceiros representam o que é e o que se deseja ser (valores). 0 conjunto destes representa o comportamento organizacional (o que se faz) que é exercitado através de práticas ligadasà competência.

Nonaka e Takeuchi (1997) tratam o conhecimento baseado em aspectos tácitos e explícitos. Ou seja, destacam a necessidade de equilibrar-se práticas formais e informais para o desenvolvimento da organização e de competências gerenciais. Conforme Sitkim (2000), as organizações mais eficientes apontadas pela literatura são aquelas que integram práticas formais e informais de controle.

A seção seguinte busca ilustrar as iniciativas desenvolvidas pelo governo e empresas australianas no intuito de construir e desenvolver competências. Trata-se de uma experiência interessante no sentido de consolidação das competências e do próprio esforço coletivo entre empresas e governo, o que se diferencia das práticas brasileiras nas quais as estratégias além de pontuais não apresentam um maior envolvimento do governo.

\section{O PROGRAMA AUSTRALIANO DE DESENVOLVIMENTO DE COMPETÊNCIAS}

Esta seção ilustra o cenário onde os estudos de caso são desenvolvidos. Ou seja, acredita-se ser fundamental conhecer os esforços e o ambiente no qual as empresasaustralianasse encontram inseridas antes de se apresentar osestudos de caso.

Tendo como base o trabalho desenvolvido por Wolf (1995), pode-se observar que theCompetence-Based Assessment (Avaliação Baseada em Competência) é a base da reforma no treinamento vocacional e sistema educacional 
- A GESTÃO DE COM PETÊNNCIAS GERENCIAISEA CONTRIBUIÇÃO DA APRENDIZAGEM ORGANIZACIONAL・•

da Inglaterra. A Austrália, seguindo o exemplo britânico, têm adotado políticas semelhantes baseada no interesse e noção de competência. Os três componentes básicos do modelo em questão, Competence-Based Assessmentsão:

1) A ênfase nos resultados - mais especificamente nos múltiplos resultados que são considerados distintamente e analisados individualmente.

2) A crença de que esses resultados devem ser específicos e observados a partir da clareza e transparência - os avaliados, avaliadores e as outras pessoas envolvidas na avaliação devem ser capazes de entender o que está sendo avaliado e os resultados esperados.

3) As especificidades na aplicação da avaliação em instituições particulares ou programas de aprendizagem (Wolf, 1995).

A pesar dessas premissas, na prática esse méto do tende a avaliar e testar conhecimentos e/ ou habilidades ao invés de pensar em competência (Wolf, 1995). Ou seja, existe uma ênfase no aspecto do desempenho (resultado). Conforme Gonzi (1992:225),

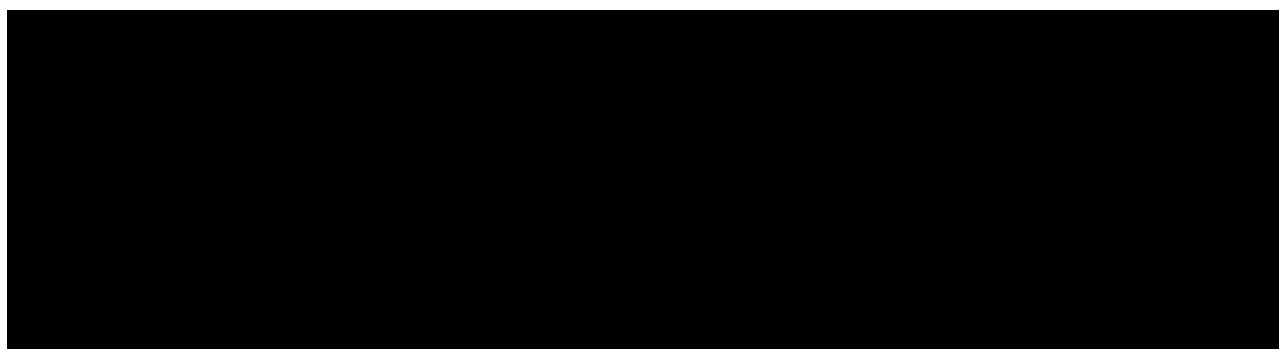

Em 1992, o governo australiano iniciou o programa conhecido como Task Force(Força Tarefa) e em 1995 foi publicado um relatório sobre os resultados observados neste programa baseado na questão da liderança e competências gerenciais conhecido informalmente comoKarpin Report ou Enterprising Nation - RenewingAustralian'sManagersto MeettheChallengesof theAsia-PadicCentury (Karpin, 1995).

O Programa Task Force buscava:

1) Desenvolver uma cultura positiva através de educação e treinamento.

2) Estimular a educação vocacional, treinamento e oferecer suporte às empresas.

3) Desenvolver talentos voltados à diversidade.

4) Alcançar as melhores práticas em gestão e desenvolvimento.

5) Reformular a educação de gestores.

A fundamentação do Programa baseava-se na crença de que "bonsgestores são a chave para uma melhor economia competitiva e melhores resultados organizacionais" (Karpin, 1995:4).

Além desses esforços apresentados, vários outros estudos tem sido reali- 
zados visando a habilitar os gerentes australianos a responderem de forma mais efetiva aos novos desafios no ambiente nacional e internacional. Dentre estes, po de-se citar The Industrial Training in Australia: The Need for Change (EFSC $\left.{ }^{3}, 1988\right)$ que apresenta a necessidade de fortalecer as competências gerenciais e recomenda missões internacionais para observar as melhores práticas relacionadas ao desenvolvimento gerencial; TheAustralian Mission on Management Skills (ESFC e DEET $\left.{ }^{4}, 1990\right)$, baseado em visita a países europeus, Estados Unidose J apão; The Mission Report (Parliament, 1991) que sugeriu recomendações para estimular o desenvolvimento de competências gerenciais; o investimento realizado em educação de gestores, treinamento e desenvolvimento em grandes empresas do setor privado (NBEET $\left.{ }^{5}, 1990\right)$. Como resultado desses esforços, em março de 1991, o ministro da Educação e Cultura anunciou o desenvolvimento do plano The Development of Managerial Skills Strategy for Australia(EstratégiasVoltadasao Desenvolvimento Gerencial) como parte da política econômica do país.

Essas iniciativas estimularam a formação e desenvolvimento gerencial e contribuíram significativamente para a construção de um perfil gerencial que buscasse vencer as carências observadasa priori relatadas como gaps significantes nesta área:entrepreneurship, orientação global, soft skills habilidadesestratégicas e desenvolvimento gerencial. Assim sendo, os gerentes australianos precisariam ser mais pró-ativos criando o portunidades e menos disperso s no sentido de se preocuparem excessivamente com práticas de outras organizações devendo focalizarem-se em seus próp prios pensamentose realidade (Karpin, 1995).

o Sistema de Desenvolvimento Gerencial proposto pode ser melhor visualizado a seguir:

\section{FIGURA}

\section{Sistema de Desenvolvimento Gerencial}

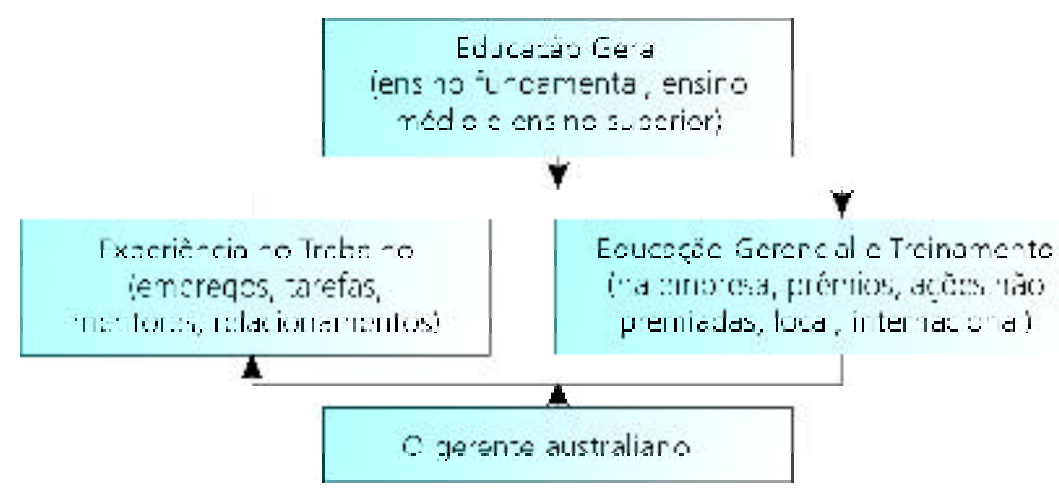

Fonte: Task Force Research: Barraclough \& Co (1995)

3 EFSC - TheEmployment and SkillsFormation Council.

4 DEET - The Department of Employment, Education and Training.

5 NBEET - The National Board of Employment, Education and Training. 
- A GESTÃO DE COM PETÊNNCIAS GERENCIAISEA CONTRIBUIÇÃO DA APRENDIZAGEM ORGANIZACIONAL・•

Finalmente, o relatório Karpin (1995) recomenda que a construção do desenho de competências gerenciais deve considerar a definição, o desenvolvimento e manutenção, e a promoção de competências flexíveis em to dos os setores industriais.

É justamente a falta de flexibilidade e desenvolvimento contínuo a base da crítica referente à construção de competências genéricas e perfil nacional de gestor, observada nas entrevistas e visitas às empresas australianas, descritas na próxima seção.

Antes de iniciar o estudo das empresas australianas é importante destacar alguns traços específicos de sua cultura, conforme os estudos desenvolvidos por Harris (2000). No ambiente das empresas australianas pode-se observar alguns contrastes em relação ao modelo predominante norte-americano:

- Os australianos não têm medo de falar o que pensam e defender seu ponto de vista.

- Enquanto os norte-americanos buscam o acordo dos colegas através de mensagens similares ou consenso, os australianos estão muito mais interessadosnos pontos de vista das pesso as que discordam.

- A importância da imagem, como as pessoas parecem ser ou se apresentam para impressionar seus pares, chefias, vizinhos, clientes etc., é fundamental para os norte-americanos. Os australianos não estão preocupados com essa questão ou com o que as pessoas pensam sobre eles. "What you see iswhat you get. Nósnão tentamos influenciar a opinião de outraspessoas a nosso respeito" (Harris, 2000:25).

Em síntese, o humor, a inovação, a amizade são características marcantes no ambiente de trabalho das empresas australianas.

Contudo, apesar da informalidade nas relações interpessoais e da aproximação entre as pesso as independentemente do nível hierárquico, existe um excesso de formalismo no que se refere à estruturação e sistematização dos programas, processos e estratégias organizacionais. "As empresas australianas são dirigidas por pesso as que são obcecadas pelo controle e quem comanda (manager) ao invés de gerenciar (lead) melhor suas ações. Este é um sério problema", afirma Harris (2000:32).

Relacionada a esta questão existe ainda o desejo de saber e controlar cada detalhe do negócio que se reflete em práticas como, por exemplo, o excesso de reuniões e o tempo desperdiçado em encontros formais quando o real problema é sufocar idéias, responsabilidades e ações.

\section{ESTUDOS DE CASOS}

A seção cinco apresenta três estudos de caso desenvolvidos em empresas 
australianas pertencentes aos setores de manufatura, construção civil e energia elétrica. Tendo em vista a proteção da identidade das empresas, serão utilizados os nomes fictícios: M anufat, Construc e Eletric.

Esta análise é desenvolvida a partir de entrevistas semidiretivas baseadas em um roteiro previamente estruturado e documentos internos. Foram entrevistadas pesso as ligadas à área estratégica, recurso s humanos, comunicação, sistema de informações, conhecimento corporativo, serviços, totalizando 13 entrevistasdeaproximadamente 2 horas.

Os estudos de caso buscam ilustrar como as empresas australianas investigadas tratam a questão das competênciasa partir da sua identificação e seleção, e ilustra práticas voltadas ao desenvolvimento de competência gerencial e aprendizagem organizacional apontadas pelasempresas.

\subsection{EMPRESA MANUFAT}

M anufat é uma empresa australiana caracterizada por práticas informais e um quadro enxuto de funcionários. Foi fundada em 1993 no intuito de auxiliar empresas australianas a desenvolver práticas organizacionais que as tornassem mais competitivas a partir do uso de uma nova tecnologia. 0 instituto oferece pesquisas aplicadas, programas educacionais e treinamentostécnicos, simulações, desenvolvimento de softwares entre outros serviços.

0 instituto busca resgatar o "elo perdido" entre a geração de uma nova idéia e a sua operacionalização. Essencialmente, Manufat opera com uma alta sofisticação em uma multidisciplinada extensão de fábricas desenvolvendo as competências das organizaçõesin-house.

\subsubsection{Competência gerencial}

Seleção - Quando a empresa seleciona novos especialistas existem certas "habilidades, ferramentas e conhecimentos requeridos", que são considerados as competências básicas desejáveis. "Nós não estamosapenas buscando habilidades básicas masestamos procurando efeitos, objetivos, planosestratégicos" (gerente administrativo financeiro). Nesse sentido, não existe um perfil genérico, cada função é diferenciada. 
- A GESTÃO DE COM PETÊNCIAS GERENCIAISEA CONTRIBUIÇÃO DA APRENDIZAGEM ORGANIZACIONAL •

A lém dessas características foram destacadas no decorrer da entrevista a questão da iniciativa, liderança e flexibilidade, tendo em vista a empresa trabaIhar num setor muito dinâmico (difusão de tecnologia). "Nós precisamos de pessoas que respondam de maneira rápida e flexível a essas mudanças" (gerente administrativo financeiro).

Desenvolvimento - A empresa não possui um programa formal de desenvolvimento de competências. Conforme o gerente administrativo financeiro, "temosquestões fundamentaisque estão bem desenvolvidas na empresa como o feedback, liderança e cada gestor busca o seu próprio desenvolvimento".

\subsubsection{Aprendizagem organizacional}

Algumas questões são relevantes para a empresa e contribuem, informalmente para o desenvolvimento de competências gerenciaise são apresentadas a seguir. Tratam-se de situações que exemplificam e ilustram a aprendizagem organizacional.

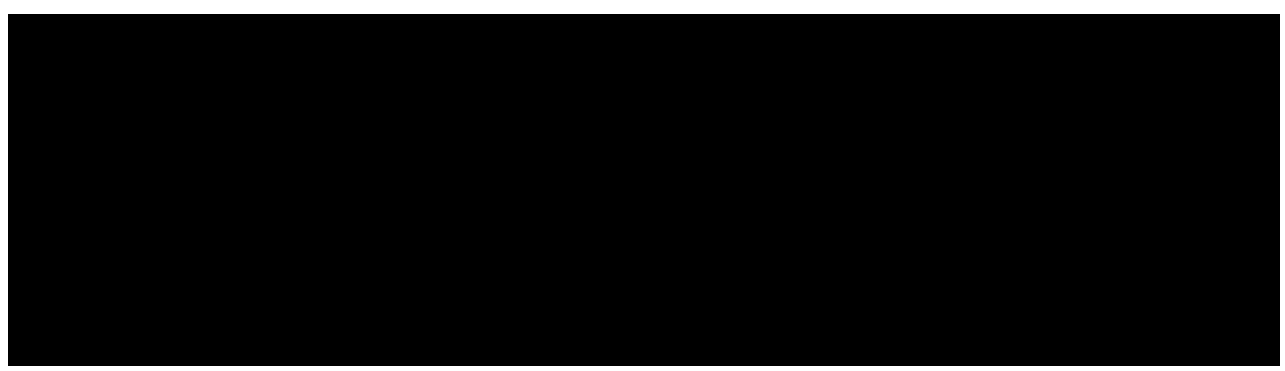

A seguir apresentam-se as situações levantadas durante a entrevista que parecem ser significativas para ilustrar exemplos de situações de aprendizagem organizacional.

Reuniões - A empresa possui três tipos principais de reuniões - a executiva, a relacionada aos programas de gestão e as reuniões de equipes. Além disso, a empresa adota a política de portas abertas. As pessoas possuem uma proximidade bastante forte e informalmente reúnem-se constantemente.

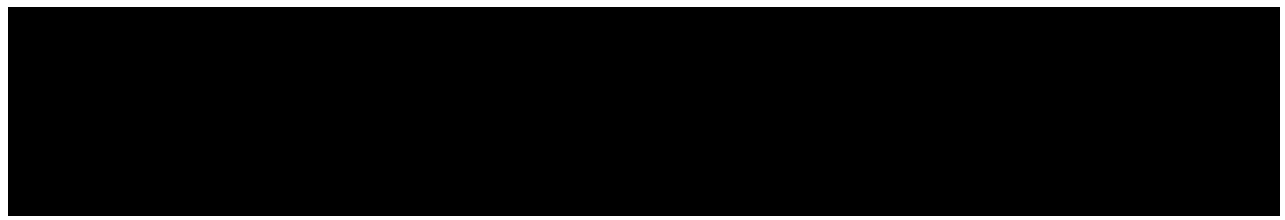

Trabalho em Equipe - A empresa organiza-se em função de trabalhos por equipe a partir de uma estrutura muito flexível. “(...) Porque eles possuem habilidades que eu não tenho e vice-versa. Então, nós precisamos trabalhar juntos para atingir melhores resultados" (gerente administrativo financeiro). 
- REVISTA DE ADM INISTRAÇÃO MACKENZIE • Ano 3, n.1, p. 135-157 •

Ser o exemplo - Abertura, comunicação e transparência.

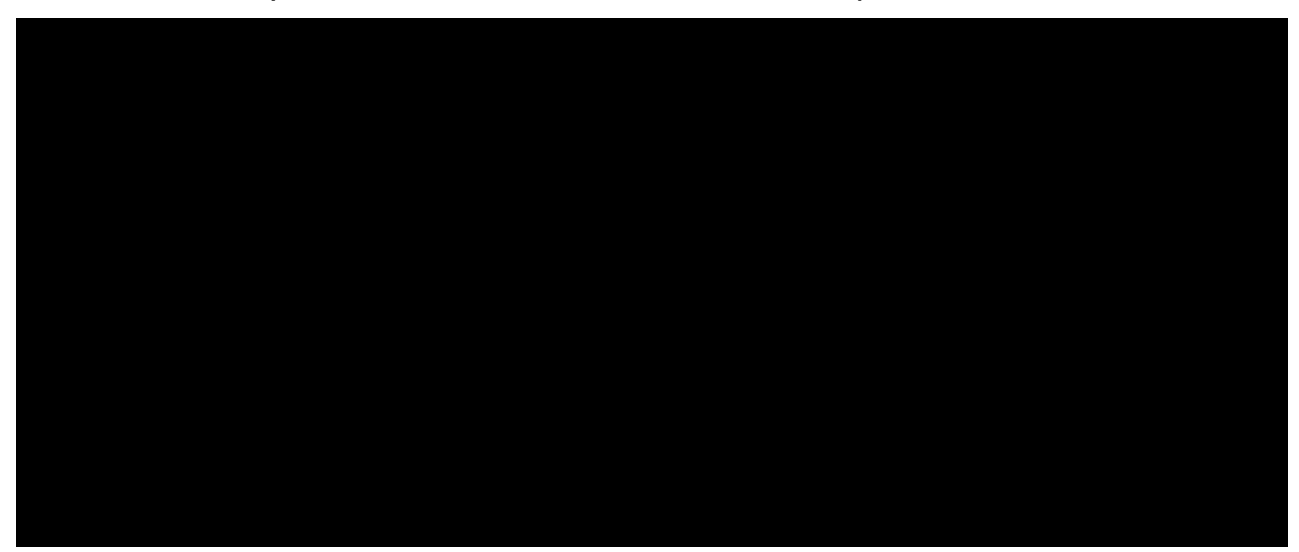

Desenvolver o cérebro e o coração - A idéia que se tem sobre competência pode ser analisada a partir do discurso do gerente administrativo financeiro.

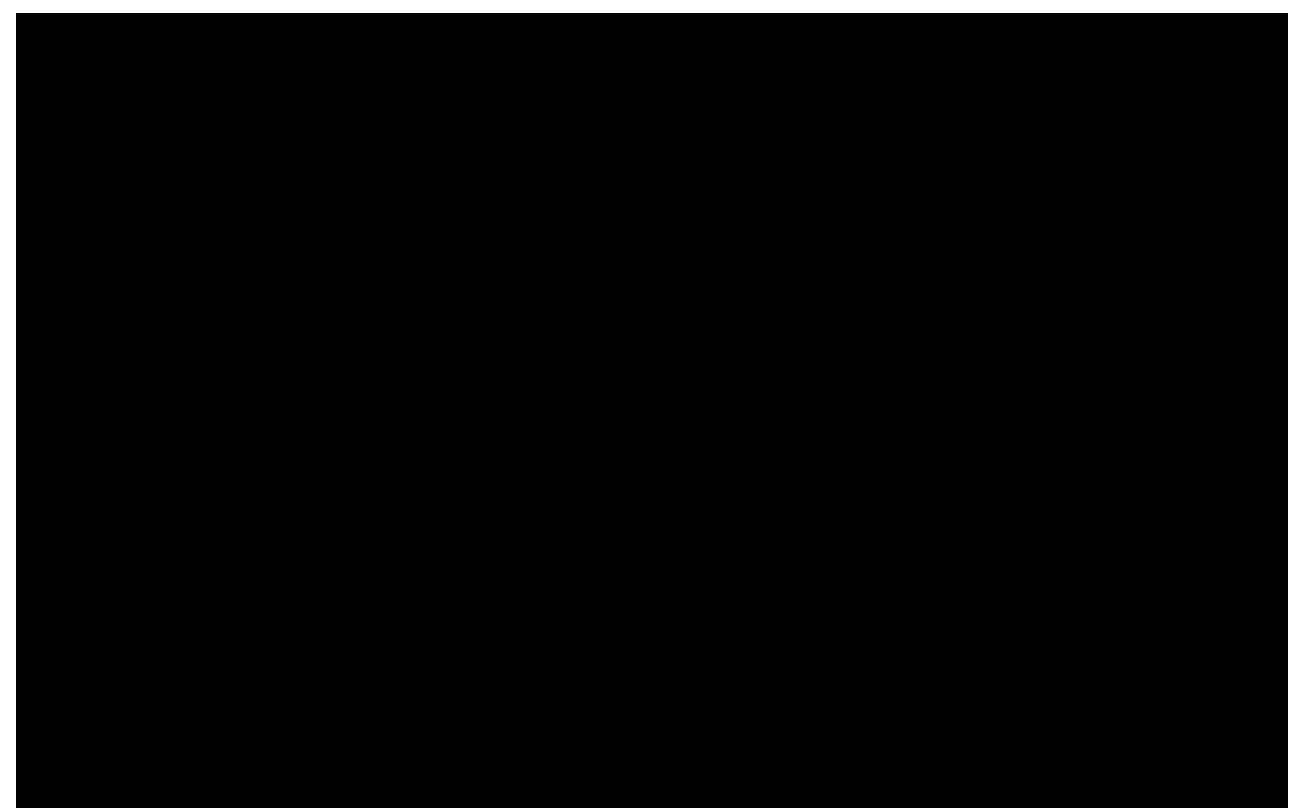

\subsection{EMPRESA CONSTRUC}

Fundada em 1930, Construc é uma das empresas australianas líderes no mercado de engenharia e construção, apresentando um capital de giro de 1,6 bilhões de dólares no ano financeiro de 1999-2000.

Possui cerca de 3.500 funcionários (aproximadamente 300 na Indonésia e 1.000 no Peru).

A empresa possui características que vão além de uma simples contratante tradicional. Existe um comprometimento a longo prazo com seusclientes ofe- 
- A GESTÃO DE COM PETÊNCIAS GERENCIAISEA CONTRIBUIÇÃO DA APRENDIZAGEM ORGANIZACIONAL •

recendo inovação, soluções a partir de projetos flexíveis, contribuindo para o crescimento da empresa em volume e qualidade de trabalho.

\subsubsection{Competência gerencial}

0 desenvolvimento de competência gerencial é relacionado ao desenvolvimento de conhecimentos e habilidades. É basicamente ligado à questão da compreensão do negócio e orientação para o consumidor. Neste sentido, os funcionários devem ser capazes de demonstrar essas habilidades aos clientes e a outros funcionários. "O objetivo com o desenvolvimento de competências gerenciaisé nos tornarmos uma Organização de Aprendizagem" (gerente técnico de serviços).

Padrões de Competência Nacional (Australian StandardsFramework) - Éo programa de desenvolvimento de competência desenvolvido pela empresa e que é baseado no relatório de Karpin ( International Competency Standard). Os aspectos centrais deste programa referem-se a autonomia, responsabilidade, complexidade de conhecimentose habilidades, contexto de aplicação, escolha de contingências, descrição e julgamento.

Seleção - Os atributos de competência considerados pela empresa são: comunicação, habilidade em nego ciação e solução de problemas visando a alcançar melhoria contínua e orientação para o cliente.

Os aspectos ligadosà atitude apontados pela empresa referem-se ao trabaIho em equipe, atitude pró-ativa, confiança, comunicação, coragem, gerenciar a diversidade, atitude de aprendizagem.

Desenvolvimento - Basicamente o desenvolvimento de competência é realizado através de treinamento e desenvolvimento.

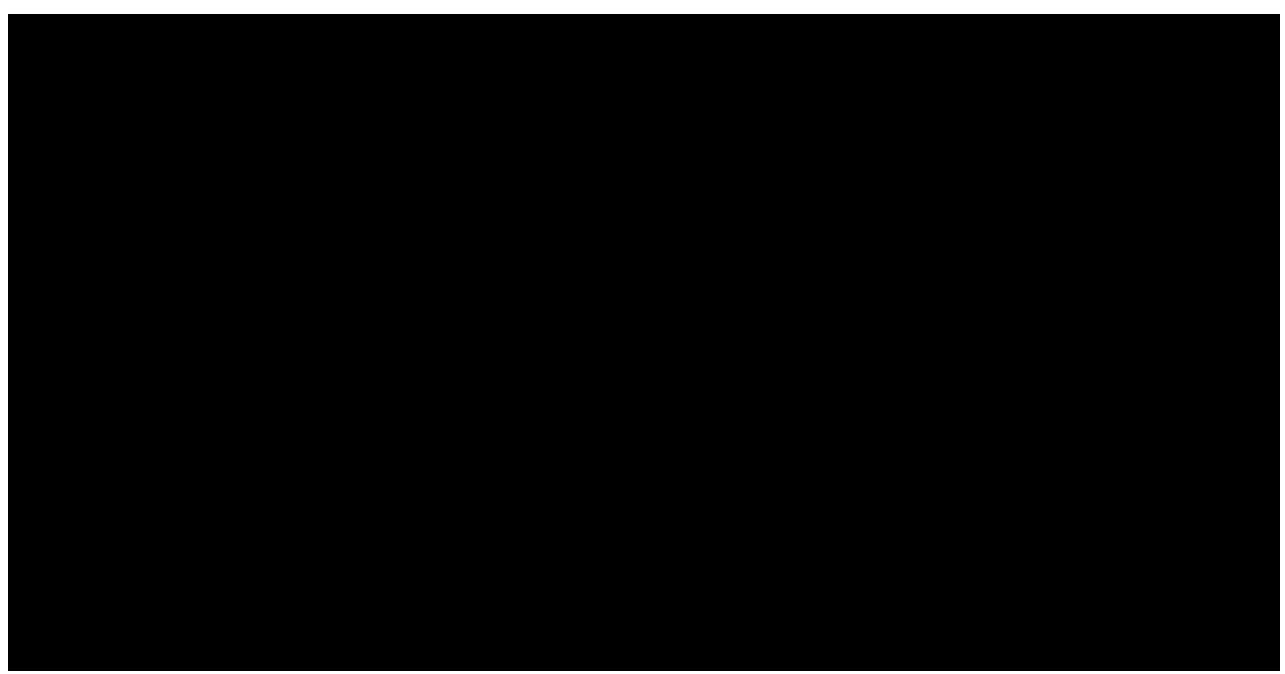


O programa de desenvolvimento da empresa incorpora:

- Cursos que fornecem conhecimentose habilidades específicas conforme as políticas e procedimentos da empresa.

- Cursos de curta duração pela Association of Professional Engineers, Scientists and M anagers - APESM A, voltadosa programas de educação contribuindo para a qualificação e empregabilidade dos funcionários, beneficiando-se ainda da experiência na sua área de atuação. Através da parceria com a APESM A, reconhecida pela qualidade de seus cursos, e a Universidade de Deakin, osfuncionários são encorajados pela empresa e possuem a opção de realizar cursos de curta duração como, por exemplo, inovação, criatividade e liderança no desenvolvimento de pessoas.

- O programa de gestão de linha de frente (FrontileneManagerProgram) que fornece educação opcional através do ensino a distância (pela APESM A).

Existe uma série de propósitos e resultados esperadosa partir do desenvolvimento de competências, ou seja a análise e desenvolvimento de competência é utilizada para: avaliações de trabalho, desenvolvimento de pessoal, recrutamento e seleção, treinamento e desenvolvimento profissional, registro profissional, análise das necessidade de treinamento e planejamento, descrição de cargos, avaliações, credenciamento de curso e qualificações, auditorias de habilidades, planejamento organizacional etc.

\subsubsection{Aprendizagem organizacional}

Existem algumas práticas de aprendizagem que podem contribuir para 0 desenvolvimento de competênciasgerenciaise são destacadasa seguir:

- Acompanhamento de mentores- supervisão no ambiente de trabalho.

- Parceria comaUniversidade deQueensland- 0 programa busca basicamente desenvolver as pessoas no que se refere à inovação, criatividade e liderança.

- Práticasinformais - Treinamento on thejob, ou como a empresa denomina: Atividades de Trabalho em Grupo. É um método de aprendizagem informal.

- Aprendizagemindividual eemgrupo- 
- A GESTÃO DE COM PETÊNCIAS GERENCIAISEA CONTRIBUIÇÃO DA APRENDIZAGEM ORGANIZACIONAL •

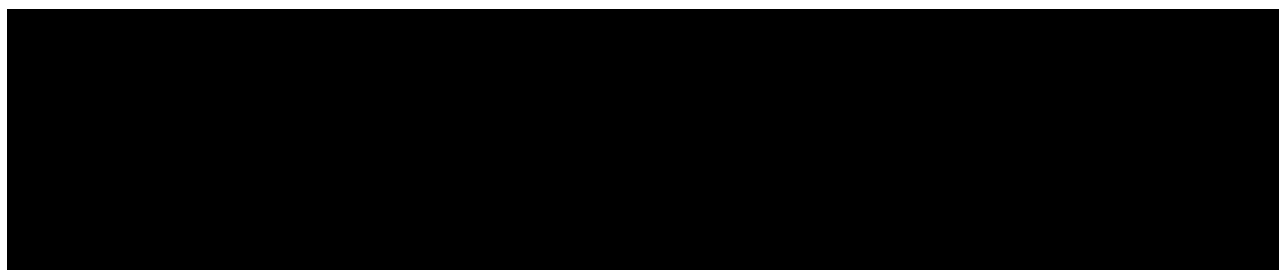

\subsection{EMPRESA ELETRIC}

Eletric é a empresa australiana líder no mercado de energia elétrica, reconhecida como world-dass range expertiseoferecendo produtose serviçospara a Austrália e outros países.

A empresa opera há mais de 75 anose conta com aproximadamente 2.100 empregados ou 3.200 se considerar a Eletric Retail.

Eletric atua ainda nos setores de telecomunicação através de uma parceria mantida com duas empresas, uma nacional e outra internacional.

\subsubsection{Competência gerencial}

Eletric está ciente da necessidade de desenvolver competências (é considerada uma empresa Competency-Based Aware) o que significa que existe um processo formal de acompanhamento e desenvolvimento de competências. "O sucesso da Eletric depende do desempenho de cada funcionário. Como existe um aumento acelerado na competição na indústria de energia, é vital que todos os funcionários da Eletric compartilhem a compreensão sobre o que eles precisam para atingir suas metas e contribuir para o sucesso da empresa. Todos os empregados devem, também, ter a oportunidade de desenvolver suas habilidades que são requeridas para o desenvolvimento de sua performancee a performance de suas equipes. Nosso processo de gestão de performance(PerformanceManagement Process) é denominado Revisão do Progresso Individual ( Individual Progress Review) que liga o que você faz no seu dia-a-dia de trabalho com a performance e sucesso da empresa" (guia de orientação para funcionários).

0 desenvolvimento de competência gerencial é visto pela empresa como uma forma de atingir melhores resultadosorganizacionaise uma prática para desenvolver as competências essenciais ( core competence).

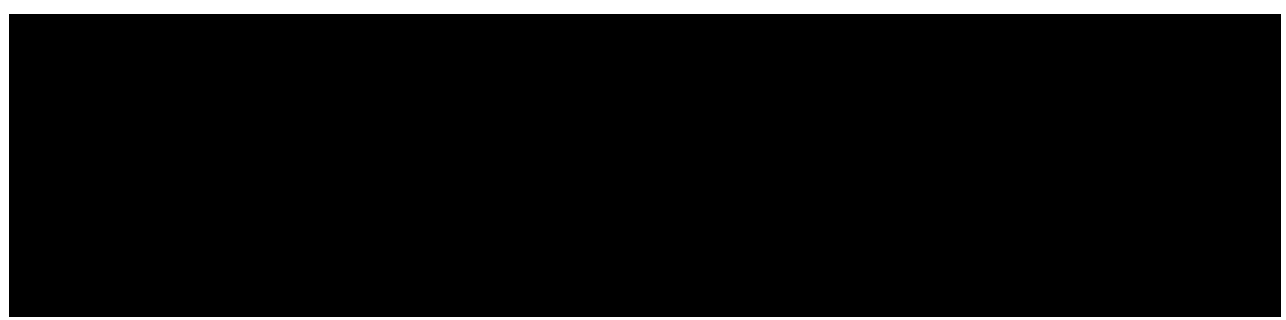


Seleção - A seleção dos atributos de competência é baseada em pesquisas realizadas com os funcionários (staff surveys), benchmarking a outras empresas e consultoria externa. "Contudo, a maior parte das idéias desenvolvidas nesta área originou-se de trabalhos de nossos especialistas internos que estão atualizados em relação a esta questão e possuem modernastécnicas". Ascompetências críticas são acompanhadas das declarações de atitudes esperadas (operacionalização das competências): liderança, serviço ao consumidor, respeito às pessoas, trabalho em equipe, responsabilidade, responsabilidade com a comunidade.

Desenvolvimento- Baseado na carência relacionada à falta de compreensão, de conhecimento sobre como se constrói uma organização, a empresa iniciou parceria com universidades (Queensland University Technology e Bond University).

- Programas de pós-graduação - Existe uma colaboração entre QUT e a empresa. A universidade forma funcionários da empresa nos cursos de pós-graduação e em contrapartida, a empresa oferece investimentos para pesquisas, equipamentos, laboratórios etc.

- Assistência aos estudos - É um processo formalizado onde os funcionários são encorajados a desenvolver suas carreiras através de todo tipo de estudo.

- Planos de desenvolvimento - O Plano de Desenvolvimento ( Development Plans) é um programa orientado para treinamento on the job baseado em atividades de aprendizagem ( on the job learning activities), que permitirá que o funcionário atinja os objetivosligados à sua avaliação de competência, melhore o desempenho atual, assuma novas responsabilidades e prepare-se para assumir novas funções (progressão de carreira).

- Aprendizados e treinamentos - Programas de treinamento administrativo para funcionáriosassistentes ( derical workers).

- Experiência prática nasférias - Auxilia estudantesa ter experiência através de trabalhos desenvolvidos durante o perío do de férias.

- Experiência profissional - Para estudantes de ensino médio.

- Conferências e cursos - A empresa incentiva a participação em conferências e cursos externos e seminários oferecendo o pagamento de todas as despesas. As pessoas são encorajadas a escrever papers para conferênciase no retorno escrevem um relatório so bre o evento.

- Universidade Eletric (EletricCollege) - Trata-se da reunião de to dos esses programa (na verdade não é uma universidade). 
- A GESTÃO DE COM PETÊNCIAS GERENCIAISEA CONTRIBUIÇÃO DA APRENDIZAGEM ORGANIZACIONAL •

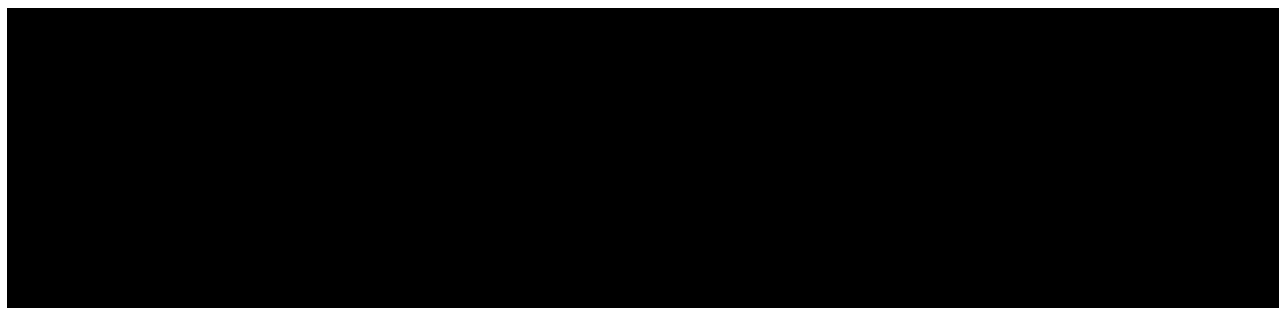

\subsubsection{Aprendizagem organizacional}

Eletric orgulha-se de ser uma organização de aprendizagem que conforme Senge (1994) é uma organização que tem como essência o conhecimento como uma forma de desenvolver:

- Domínio pessoal (aprendizagem individual)

- Modelos mentais (aprendizagem individual)

- Visão compartilhada (aprendizagem em grupo)

- Trabalho em Equipe (aprendizagem em grupo)

- Raciocínio sistêmico (aprendizagem organizacional)" (Board memorandum - knowledge value and the learning organization).

Existem algumas práticas de aprendizagem na empresa que contribuem para o desenvolvimento de competências gerenciais que são destacadas a seguir:

- Workshopse reuniões - A empresa trabalha orientada por projetos. Aspessoas são reconhecidas pelas suas diferentes habilidades em diferentes áreas da empresa e, também, por sua interação e discussão no que se refere à transferência de conhecimento. Então, "definitivamente, existe uma forte interação" (gerente de conhecimento corporativo).

- Memória organizacional - Existe uma grande memória organizacional. M uitas pessoas deixaram a empresa por causa das mudançasorganizacionais (corporatização ou corporatisation ${ }^{6}$ ) e do processo de downsizing.

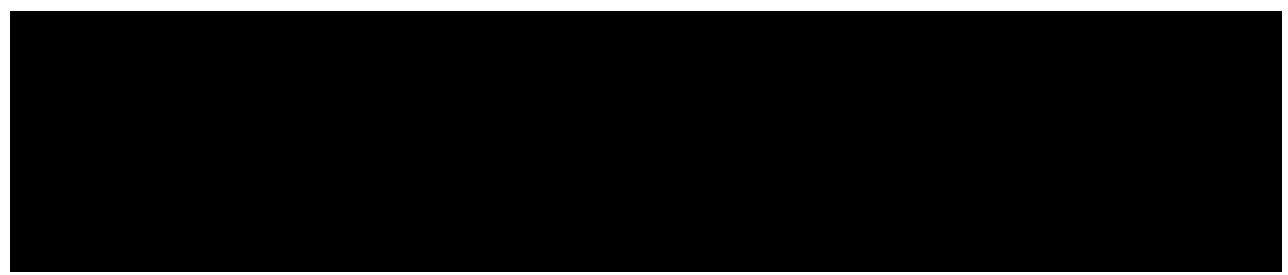

6 Corporatization - A palavra foi traduzida como corporatização, para este trabalho, e caracteriza-se por um processo intermediário entre a situação de empresa pública e empresa privada. 
- Tensão criativa (zona de conforto)- Osgerentes precisam desenvolver competências para enxergar os treinamentos não como uma solução imediata para os problemas.

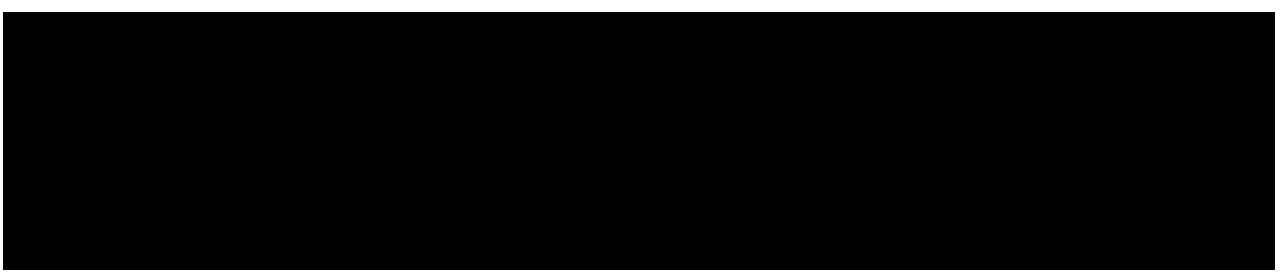

- Comunicação - Intranet e projetosem rede (web project). - Na Intranet estão todas as políticas, informações, operações etc. Existe um boletim corporativo que é publicado todos os dias às 3 horas da tarde onde as pessoas podem vender coisas, conferir os novos acontecimentos, eventos sociaise esportivos, ver as informações mais recentes da empresa em relação a seus processos e negócios. "Todas as informações, formulários, reclamações, tudo está lá" (gerente de conhecimento corporativo).

- Ética-

Apesar do orgulho em ser reconhecida como uma organização de aprendizagem, na prática a situação é diferente. 
- A GESTÃO DE COM PETÊNNCIAS GERENCIAISEA CONTRIBUIÇÃO DA APRENDIZAGEM ORGANIZACIONAL・•

\section{CONCLUSÕES}

O paper apresentado busca lançar novas luzes sobre uma área ainda não suficientemente explorada, relacionada ao desenvolvimento de competências gerenciais e A prendizagem Organizacional. Este fato reforça a importância do estudo e dos resultadosa ser atingidos em futuras pesquisas, ap resentando-se ainda, como um desafio a sistematização do processo de aprendizagem organizacional a partir da análise do desenvolvimento de competências gerenciais tendo em vista as poucas referências bibliográficas que tratam as questões simultaneamente.

Salienta que as práticas organizacionais voltadas ao desenvolvimento de competências gerenciais e à aprendizagem organizacional devem ser construídas internamente em cada organização respeitando a sua história, experiência, cultura etc., enfim, a sua identidade (especificidade). As práticas de aprendizagem organizacional observadas caracterizam-se como um processo de tentativa e erro carente de significado. Neste sentido, observa-se o excesso de práticas formais nas empresas Construc e Eletric que parecem não resolver a questão da sistematização. As práticas formais, aparentemente suficientes para resolver a questão apontada pela A prendizagem Organizacional no que se refere à consolidação de suas práticase à articulação entre as competências gerenciais com outras estratégias organizacionais não são efetivas. 0 equilíbrio entre práticas formais e informais talvez possa responder melhor a esta questão da sistematização.

Destaca-se a importância da participação do governo nas iniciativas voltadas ao desenvolvimento das competências como um incentivo na construção e consolidação de competências genéricas que são a base para os programas das empresas. Contudo, é no âmbito organizacional que essas competências são detalhadas e apropriadas conforme a realidade individual de cada organização. Portanto, o exemplo australiano retrata a parceria entre governo e empresas como uma estratégia eficiente que atende as necessidades e demandas do país.

A partir dos estudos de casos realizados, pode-se constatar que:

1. Existe uma tipologia específica para a definição de competência gerencial em cada organização investigada (lista de atributos). A pesar do esforço do governo australiano em buscar desenvolver competências genéricas, no plano organizacional a construção dessas competências, como não poderia deixar de ser, retrata a situação individual e as estratégias de cada organização.

2. A competência gerencial necessita estar, de alguma forma, relacionada com o negócio da empresa. Ou seja, parte-se da análise dacore competence para se chegar ao managerial competencies. Esta talvez seja a justificati- 
va mais consistente para a construção de competências específicas em cada organização apesar da iniciativa governamental de construção de competênciasgenéricas.

3. Existe a necessidade de buscar o equilíbrio entre as práticas formais e informais nas organizações. As práticas formais são necessárias para que as organizações exercitem a sua capacidade de sistematização e construção da memória organizacional. Porém, é através de práticas informaisque incentivam a aproximação entre aspessoas que as competências voltadas, por exemplo, ao relacionamento interpessoal se desenvolvem.

4. Há uma carência no que se refere ao comprometimento das pessoas e construção de uma visão compartilhada para que os resultados sejam efetivos. A questão da articulação entre as estratégias e práticas organizacionais necessita ser tratada não apenas na esfera estratégica masé importante que cada funcionário tenha uma noção para onde a empresa caminha e qual a sua contribuição nesse processo.

5. Observa-se a necessidade de se repensar a questão do autodesenvolvimento. As empresas australianas, neste sentido, adotam uma postura paternalista promovend o e oferecendo eventos e treinamentosformais reforçando uma postura mais passiva dos funcionários no sentido de buscar o seu próprio desenvolvimento.

6. A Aprendizagem Organizacional pode ser uma estratégia efetiva para o desenvolvimento de competência gerencial tendo em vista estimular pontos críticos nesse processo como a questão da articulação entre estratégia e processos, interação entre as pessoas e abordagem coletiva. Ou seja, a questão da articulação pode ser melhor compreendida a partir do raciocínio sistêmico, a interação tem como base a aprendizagem em grupo e a abordagem coletiva é a essência da A prendizagem Organizacional, uma vez que a ênfase recai so bre as práticas organizacionais desenvolvidas em grupos e não em esforços individuais.

Finalmente, destaca-se que esse paper representa a etapa exploratória da tese de doutorado da autora. Espera-se poder contribuir, de alguma forma, para um maior embasamento conceitual da área temática, seja pela utilização de uma abordagem inovadora, ou ainda, pela questão da complementaridade de estudos realizados nesta área.

\section{REFERÊNCIA S}

ARGYRIS, C. On Organizational Learning. Massachusetts: Blackwell Publisers, 1992.

DODGSON, M. Organizational Learning: a review of some literatures. Organization Studies, p. 375394, 1993.

DURAND, T. Forms of Competence. ProceedingsFourth International Conference on CompetenceBased Management. In: BRANDÃO, H.; GUIM ARÃES, T., ENANPAD, Foz do Iguaçu, 1999. 
- A GESTÃO DE COM PETÊNCIAS GERENCIAISE A CONTRIBUIÇÃO DA APRENDIZAGEM ORGANIZACIONAL •

DUTRA, J.; SILVA, J. Gestão de Pessoaspor Competência. In: ENANPAD, Foz do Iguaçu, 1998.

EBOLI, M. Universidade Corporativa (mimeo), 1999.

FLEURY, M. Gestão de Competência (mimeo), 1999.

GARVIN, D. Building a Learning Organization. Harvard Business Review, p. 78-91, jul./aug. 1998.

GONCZI, A. Developing a CompetentWorkforce. Adelaide: National Center for Vocational Education Research, 1992.

HAM EL, G.; PRAHALAD, C. K. Competindo pelo Futuro. Rio de Janeiro: Campus, 1995.

HARRIS, A. They don't call them septics for nothing. The Administrative Financial Review, sep. 2000.

M anagement or Leadership? Australia ticks the wrong box. The Administrative Financial Review, apr. 2000.

KANTER, R. Quando osGigantesA prendema Dançar. Rio de Janeiro: Campus, 1997.

KARPIN, D. Enterprising Nation- Rewarding Australia'sManagersto Meet theChallengesof the AsiaPacific Century. Executive Summary, apr. 1995.

KIM , D. The Link Between Individual and Organizational Learning. Sloan Management Review, $p$. 37-50, 1993.

KOLB, D. A Gestão e o Processo de A prendizagem. In: Starkey, K. Como asOrganizaçõesA prendem. São Paulo: Futura, 1997.

KUBR, M.; ABEL, D. M anagers and Their Competences. Management Development. Geneva: ILO, 1998.

LE BOTERF. Construire la Competence Collective de Lémtreprise. Gestion, v. 22, n. 3, Automne, 1997.

MAGALHÃES, S.; ROCHA, M. Desenvolvimento de Competências: o futuro agora! Revista de Treinamento eDesenvolvimento, p.12-14. São Paulo, jan. 1997.

MARQUARDT, M ichaelJ.Building aleamingorganization:asystemapproachto quantumimprovement and global success. New York: McGraw-Hill, 1996.

M ORGAN, G. Imagens da Organização. São Paulo: Atlas, 1996.

MOSCOVICl, F. Equipes Dão Certo. Rio de Janeiro: José Olympio, 1994.

NONAKA, I.; TAKEUCHI, H. Criação de Conhecimento na Empresa. Rio de Janeiro: Campus, 1997.

RIBEIRO, L.; GUIM ARÃES, T. Competências Organizacionaise Humanasde uma Organização Financeira Estatal: o ponto de vista de seusgerentes. Foz do Iguaçu: ENANPAD, 1999.

ROPÉ, F. TANGUY, L.Saberese Competências o uso de taisnoçõesna escola ena empresa.Campinas: Papirus, 1997.

RUAS, R. CompetênciasGerenciaiseAprendizagemnasOrganizações uma relação defuturo?Seminário Internacional de Competitividade Baseada no Conhecimento. São Paulo: ago. 1999.

SANDBERG, J. Understanding Leadership froma Social Construction Perspective. Seminar, University of Queensland, 24 aug. 2000.

SENGE, P. A Quinta Disciplina. São Paulo: Nova Cultural, 1990.

SPENCERJR, L. Competence and Work: modelsfor superior performance. New York:J ohn Wiley \& Sons, 1993.

SPENCER, L.; SPENCER, S. Competence at Work. New York: John W iley \& Sons, 1993.

SWIERINGA, J.; WIERDSM A, A. La Organización que Aprende. BuenosAires: 1992.

VAILL, P. Learning asa Way of Being. San Francisco: J ossey-Bass Publishers, 1996.

VERGARO, S. Competências Gerenciais Requeridas em Ambiente de M udança. Revista Brasileira de Administração Contemporânea, p. 49-75, set. 1995.

WOLF, A. Competence-Based Assessment. Buckingham: Open University Press, 1995.

ZARIFIAN, P. A Gestão pela Competência. Rio de Janeiro: Centro Internacional para a Educação, Trabalho e Transferência de Tecnologia, 1996. 